\title{
Thermal Decomposition of Diphenyl Tetroxane in Chlorobenzene Solution
}

\author{
Alexander G. Bordon, Andrea N. Pila, Mariela I. Profeta, María J. Jorge, Lilian C. Jorge, \\ Jorge M. Romero, Nelly L. Jorge
}

Laboratorio de Investigación en Tecnología Ambiental, Facultad de Ciencias Exactas, Naturales y Agrimensura de la Universidad Nacional del Nordeste, Corrientes, Argentina

Email: nelly.jorge@gmail.com

How to cite this paper: Bordon, A.G., Pila, A.N., Profeta, M.I., Jorge, M.J., Jorge, L.C., Romero, J.M. and Jorge, N.L. (2019) Thermal Decomposition of Diphenyl Tetroxane in Chlorobenzene Solution. International Journal of Organic Chemistry, 9, 1-9. https://doi.org/10.4236/ijoc.2019.91001

Received: November 26, 2018

Accepted: January 11, 2019

Published: January 14, 2019

Copyright $\odot 2019$ by author(s) and Scientific Research Publishing Inc. This work is licensed under the Creative Commons Attribution International License (CC BY 4.0). http://creativecommons.org/licenses/by/4.0/

\begin{abstract}
The thermal decomposition of Cyclic Diperoxide of Benzaldehyde 3,6-diphenyl-1,2,4,5-tetroxane, (DFT) in chlorobenzene solution in the studied temperature range $\left(130^{\circ} \mathrm{C}-166^{\circ} \mathrm{C}\right)$ satisfactorily satisfies a first order law up to $60 \%$ conversions of diperoxide. DFT would decompose through a mechanism in stages and initiated by the homolytic breakdown of one of the peroxidic bonds of the molecule, with the formation of the corresponding intermediate biradical. The concentration studied was very low, so that the effects of secondary reactions of decomposition induced by free radicals originated in the reaction medium can be considered minimal or negligible. The activation parameters for the unimolecular thermal decomposition reaction of the DFT are $\Delta \mathrm{H} \#=30.52 \pm 0.3 \mathrm{kcal} \cdot \mathrm{mol}^{-1}$ and $\Delta \mathrm{S} \#=-6.38 \pm 0.6 \mathrm{cal} \cdot \mathrm{mol}^{-1}$ $\mathrm{K}^{-1}$. The support for a step-by-step mechanism instead of a process concerted is made by comparison with the theoretically calculated activation energy for the thermal decomposition of 1,2,4,5-tetroxane.
\end{abstract}

\section{Keywords}

DFT, Thermal Decomposition, Chlorobenzene, Mechanism

\section{Introduction}

Peroxides have been widely used in several areas of chemistry due to their high reactivity [1]. Due to their specific properties as initiators of free radical reaction they are widely used in synthetic chemistry [2], especially in polymerization processes [3]. At present, it has been discovered that tetroxanes possess an impressive antimalarial activity [4] and herbicide activity. The association between the functional group of peroxide and the antimalarial activity allows the devel- 
opment of new antimalarial drugs [4] [5] [6]. Unfortunately, several members of this composite class are very unstable; only a small number is easy to handle with adequate security and are available as commercial products.

The thermal decomposition of tetraderivates of 1,2,3,4-tetroxanes have been studied in solution and gas phase. The mechanism of thermal decomposition was evaluated in solution [7] [8] [9].

Unimolecular thermal decomposition can happen by two different kinds:

1) A stepwise homolysis initiated by rupture of peroxidic bond with intermediate biradical formation

2) A concerted mechanism where peroxidic bond breaking and peroxidic bond making may occur simultaneously.

Both processes in the thermolysis of tetroxanes give ketone or aldehyde and molecular oxygen as reaction products.

In previous theoretical studies, it was determined that in the gas phase the mechanism of the thermal decomposition reaction for 1,2,4,5-tetroxane is a mechanism in stages and not concerted [10].

In our research group, the kinetics and reaction mechanism of the 3,6-diderivatives of tetroxane in different solvents including 3,6-diphenyl-1,2,4,5-tetroxane were investigated the influence of solvents with different physicochemical characteristics [11] [12] [13] [14].

This work has been performed to understand the kinetics and the mechanism thermal decomposition of 3,6-difenil-1,2,4,5-Tetroxane, (DFT) in solution of chlorobenzene These kinetic studies are intended to analyze the solvent effect on the parameters governing the reaction. Steric effects, inductive, mesomeric and stereoelectronic of the substituents on peroxidic ring are considered in relation by the force of peroxidic bond.

\section{Materials and Methods}

\subsection{Synthesis}

DFT was prepared by drop wise addition of $7.2 \mathrm{~mL}$ benzaldehyde (Fluka) in 20 $\mathrm{mL}$ ethanol solution to a vigorously stirred and cooled $\left(-20^{\circ} \mathrm{C}\right)$ mixture of $56 \%$ hydrogen peroxide and sulfuric acid. After stirring for 2 hs, a microcrystalline white solid was obtained.

It was repeatedly washed with water and further purified by recrystallizing from methanol. The DFT purity was checked by GC. The structure and conformation was confirmed by NMR, obtaining the same results as in previous synthesis [15].

\subsection{Kinetics Methods}

Pyrex glass tubes ( $8 \mathrm{~mm}$ i.d., $10 \mathrm{~cm}$ length) filled with the appropriated volume of DFT in chlorobenzene solution, with added n-octane (internal standard) were thoroughly degassed in the vacuum line at $-196^{\circ} \mathrm{C}$ and then sealed with a flame torch. 
These Pyrex glass tubes were submerged in a thermostated silicone oil bath $\left( \pm 0.1^{\circ} \mathrm{C}\right)$ to temperatures between $130^{\circ} \mathrm{C}$ and $166^{\circ} \mathrm{C}$. There were withdrawn after selected times and cooling rapidly to $0^{\circ} \mathrm{C}$ to stop the reaction

It was conserved to $-18^{\circ} \mathrm{C}$ up till its analysis with GC.

\subsection{Analysis of Remaining Reagent}

The remaining DFT was evaluated by Gas Chromatographer AGILENT 7890A, with FID detector, using nitrogen like carrier gas and quantitative method of n-octane (internal standard). The capillary column used was HP5-Agilent (stationary phase: (5\%-Phenyl)-methylpolysiloxane, length $25 \mathrm{~m}$, film $0.33 \mu \mathrm{m}$, id. $0.2 \mathrm{~mm}$ )

General conditions:

Injector temperature $150^{\circ} \mathrm{C}$,

Detector temperature $300^{\circ} \mathrm{C}$.

Oven with progameted temperature:

$\mathrm{Ti}=50^{\circ} \mathrm{C}$ initial, $\mathrm{Ti}=1 \mathrm{~min}$.

Ramp of $20^{\circ} / \mathrm{min}, \mathrm{FT}=220^{\circ} \mathrm{C}$ and $\mathrm{Tt}=15 \mathrm{~min}$.

Sample volume: $1 \mu \mathrm{L}$.

The measurement of the areas of the chromatographic peaks was made using the EZ Crom software.

\subsection{Calculations Methods}

Rate constant values were calculated by a mean square data treatment $(r>0.998)$ and the parameters values of activation were obtained by computational method employing the Eyring and Arrhenius equations and the corresponding error limits with a method executed with a computational treatment.

\section{Results and Discussion}

The thermal decomposition of the DFT in solution of chlorobenzene in the range studied, as shown in Table 1 (Figure 1) meet a first order kinetic law up to $60 \%$ conversion of the DFT.

The influence of temperature on the rate constant values of DFT (kexp) in chlorobenzene solution corresponding to the unimolecular decomposition reaction, can be represented by the Arrhenius equation, where the value of the

Table 1. Rate constant values for DFT thermal decomposition reaction in chlorobenzene solution at different temperatures.

\begin{tabular}{cccc}
\hline $\mathrm{T}\left({ }^{\circ} \mathrm{C}\right)$ & {$[\mathrm{DFT}] \times 10^{-3} \mathrm{M}$} & $k \times 10^{5} \mathrm{~s}^{-1}$ & $r^{2}(n) a$ \\
\hline 130 & 1.0 & 0.88 & 0.987 \\
140 & 1.0 & 2.21 & 0.997 \\
150 & 1.0 & 7.55 & 0.988 \\
166 & 1.0 & 20.34 & 0.986 \\
\hline
\end{tabular}

${ }^{\mathrm{a}}$ Errors calculated as in ref. [11]. 


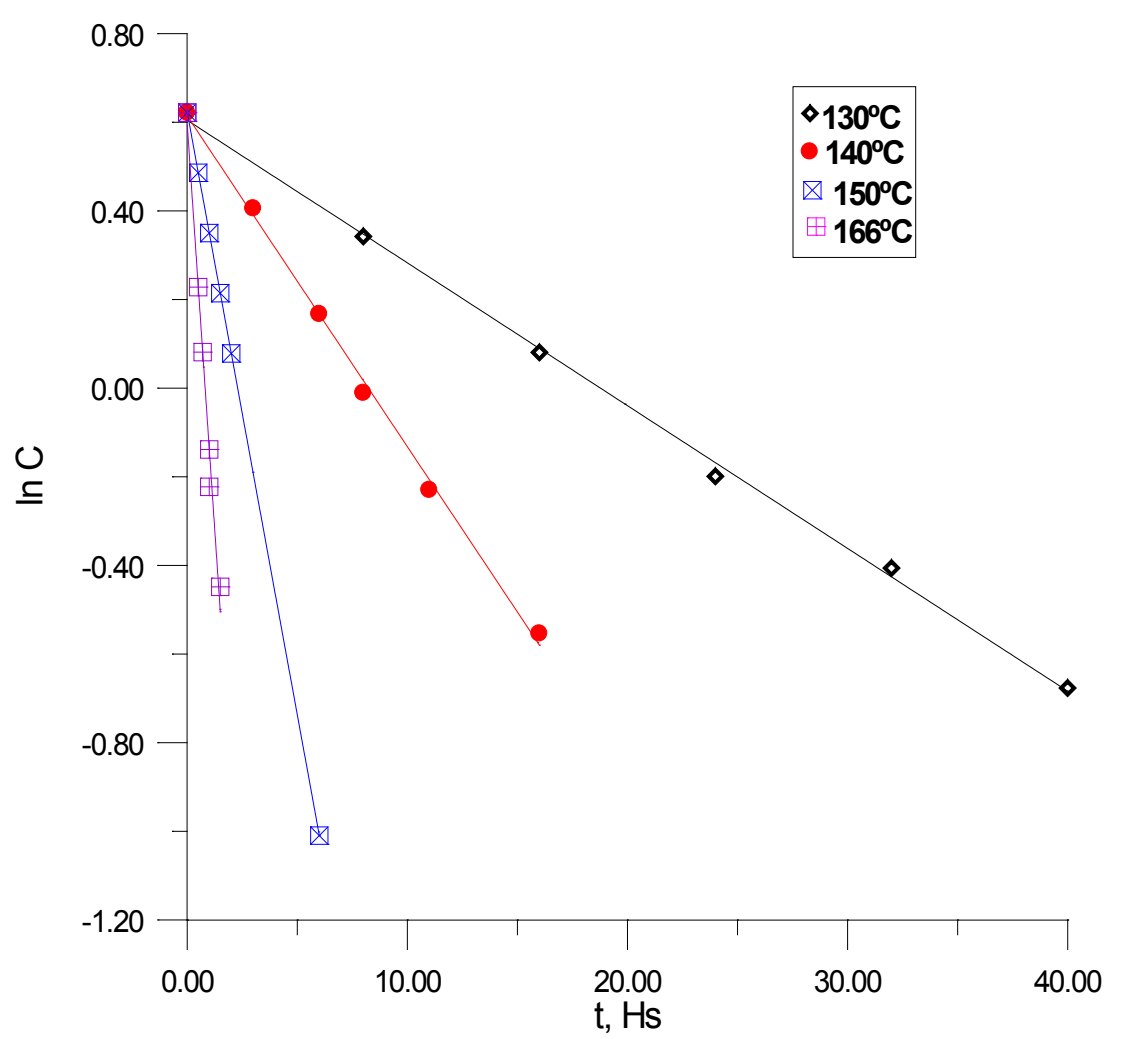

Figure 1. Kinetic of DFT thermal decomposition reaction in chlorobenzene solution at different temperatures.

activation energy is expressed in $\mathrm{kJ} \cdot \mathrm{mol}^{-1}$ and the errors correspond to the standard deviations derived from a treatment of the kinetic data by a method of minimum squares, $r^{2}(n)$ a. Equation (1).

$$
\ln k\left(s^{-1}\right)=(28.25 \pm 0.8)-(31.92 \pm 4.0) / R T
$$

The linearity of the Arrhenius equation $\left(r^{2}=0.987\right)$ over a relatively wide temperature range $\left(40^{\circ} \mathrm{C}\right)$ suggests that the calculated activation parameters (activation energy and pre-exponential factor), for the DFT reaction in chlorobenzene correspond to a simple process represented by the homolytic breakdown of the O-O bond, (Scheme 1).

This intermediate biradical in the condition experimental, can undergo subsequent reactions involving $\mathrm{C}-\mathrm{O}$ bond breaks, justifying the appearance of benzaldehyde with a $50 \%$ yield, or C-C cleavages giving rise to phenyl radicals, which then react with the solvent extracting hydrogen to form a biphenyl and two phenyl radicals are bound to give biphenyl (Scheme 2).

The products of the reaction were confirmed by mass spectrometry with HP5890-Series II plus chromatograph.

The values of the activation parameters $\left(\Delta \mathrm{H}^{\#}=30.52 \pm 0.3 \mathrm{kcal} \cdot \mathrm{mol}^{-1}\right.$ and $\Delta \mathrm{S}^{\#}$ $=-6.38 \pm 0.6 \mathrm{cal} \cdot \mathrm{mol}^{-1} \mathrm{~K}^{-1}$ ) corresponding to the thermolysis of DFT in chlorobenzene solution were determined using Eyring's equation [16], whose graphical representation (Figure 2$)$ is practically linear $\left(r^{2}=0.984\right)$ over a wide range of 


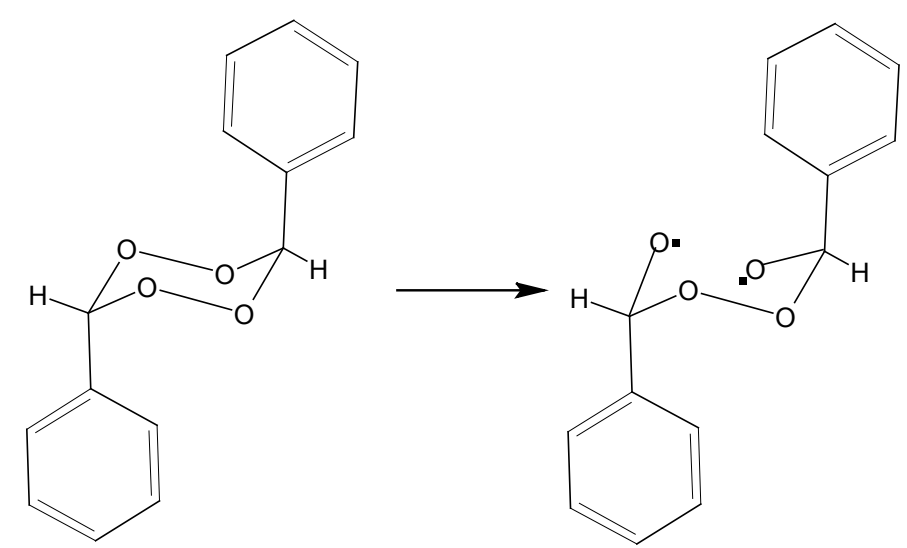

Scheme 1. Homolytic rupture of O-O bond.

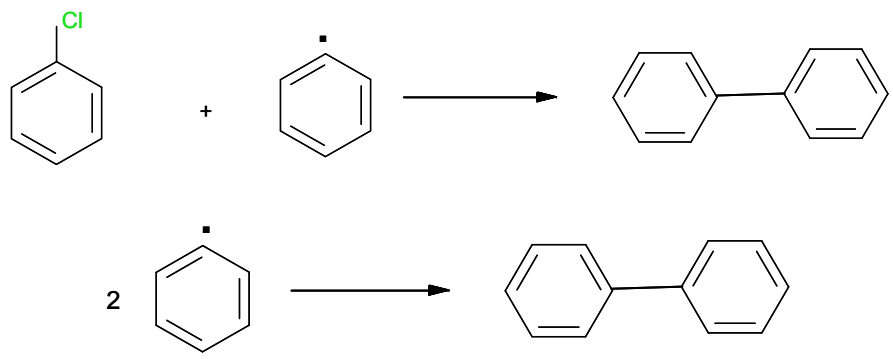

Scheme 2. Biphenyl formation.

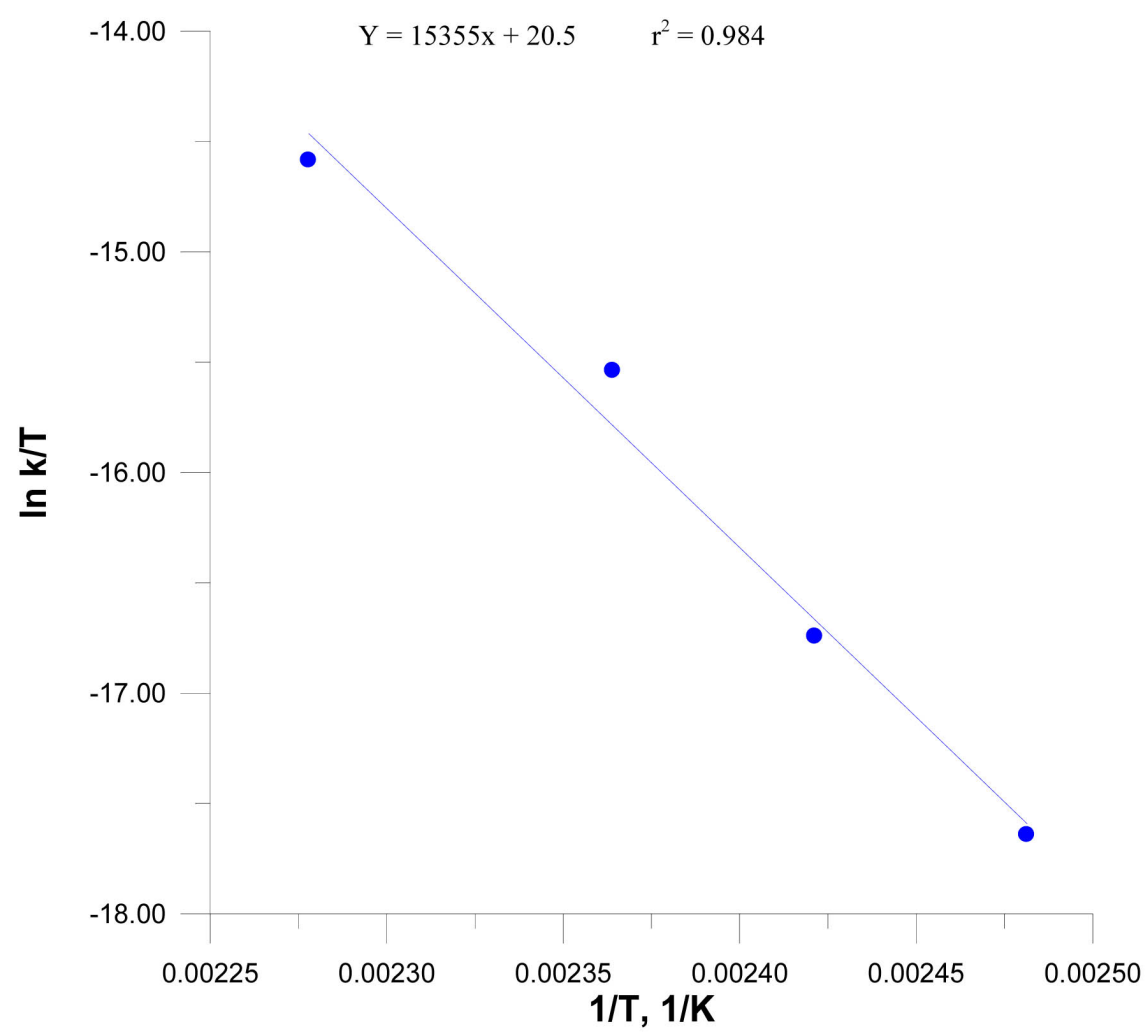

Figure 2. Graphical representation of the Eyring equation for the thermal decomposition of the DFT in chlorobenzene solution. 
temperatures $\left(\Delta \mathrm{T}=40^{\circ} \mathrm{C}\right)$. The values of the enthalpy variation are similar to those corresponding to the homolytic decomposition of other cyclic diperoxides already studied.

This suggests that the determinant stage of the reaction rate in the thermolysis of the DFT is the rupture of the peroxidic bond with formation of the intermediate biradical.

The variation of the activation entropy results in a negative value. This is explained because the DFT is a disubstituted diperoxide that has a low steric hindrance, which results in a higher degree of solvation of the activated complex, causing a decrease in the activation entropy.

This suggests that the determinant stage of the reaction rate in the thermolysis of the DFT is the rupture of the peroxidic bond with formation of the intermediate biradical.

The variation of the activation entropy results in a negative value. This is explained because the DFT is a disubstituted diperoxide that has a low steric hindrance, which results in a higher degree of solvation of the activated complex, causing a decrease in the activation entropy.

The principal products generated in the decomposition of DFT in chlorobenzene solution were benzaldehyde and molecular oxygen (Scheme 3 ).

\section{Analysis of the Results Obtained in the Thermolysis of the DFT in Chlorobenzene and Other Solvents Previously Studied}

If we try to understand the influence that the solvent can have on the kinetics of the decomposition reaction, we will have to analyze the kinetic parameters in different solvents of the DFT (Table 2).

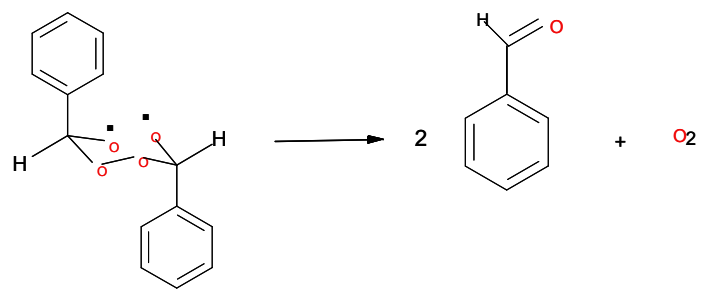

Scheme 3. Formation of benzaldehyde and molecular oxygen.

Table 2. Activation parameters of the thermal decomposition of DFT in different solvents.

\begin{tabular}{ccccc}
\hline Solvente & $\begin{array}{c}\mathrm{E}_{\mathrm{a}} \\
\mathrm{Kcal} / \mathrm{mol}\end{array}$ & $\begin{array}{c}\Delta \mathrm{H}^{0 \#} \\
\mathrm{Kcal} / \mathrm{mol}\end{array}$ & $\begin{array}{c}\Delta \mathrm{S}^{0 \neq} \\
\mathrm{Cal} / \mathrm{mol} \mathrm{K}\end{array}$ & $\begin{array}{c}\Delta \mathrm{G}^{0 \neq} \\
\mathrm{Kcal} / \mathrm{mol}\end{array}$ \\
\hline Benzene & $32.4 \pm 0.4$ & $32.8 \pm 0.4$ & $-5.2 \pm 1.2$ & $35.0 \pm 0.4$ \\
Chlorobenzene & $31.9 \pm 4.0$ & $30.5 \pm 0.3$ & $-6.4 \pm 0.6$ & $33.2 \pm 0.3$ \\
Toluene & $31.6 \pm 0.6$ & $30.8 \pm 0.6$ & $-7.9 \pm 1.5$ & $34.1 \pm 0.6$ \\
Tetrahydrofuran & $28.1 \pm 0.4$ & $27.2 \pm 0.4$ & $-11.8 \pm 0.5$ & $32.2 \pm 0.4$ \\
Metanol & $25.4 \pm 0.8$ & $24.8 \pm 0.8$ & $-16.5 \pm 1.8$ & $31.7 \pm 0.8$ \\
Metilcellosolve & $21.0 \pm 1.0$ & $20.2 \pm 1.0$ & $-25.3 \pm 1.4$ & $30.8 \pm 1.0$ \\
\hline
\end{tabular}


According to the transition state theory, solvents can modify the activation parameters of the thermolysis reactions according to the degree of solvation of the reactants and activated complex.

The rate constant of the reaction is determined by the speed with which the activated complex passes the energy barrier in the direction of product formation. If the reaction is carried out in solution, the DFT can be solvated with different scope, according to the solvation power of the solvent used.

These differences can accelerate or retard the reaction, varying the reaction rate.

The relationship between entropy and the enthalpy of activation of a reaction is not easy to analyze. However, when evaluating the data obtained in this work with the facts above, it can be seen that a change in the value of the enthalpy $\left(\Delta \mathrm{H}^{0 *}\right)$ is accompanied by a change in the same sense of the activation entropy $\left(\Delta S^{0 \#}\right)$ [17] [18]. This phenomenon is known as Compensation Effect or Isokinetic Ratio. [17] [18] (Figure 3).

The linearity observed in this representation shows the compensation effect for the DFT in all the solvents studied.

\section{Conclusions}

Thermal decompositions reaction of DFT in chlorobenzene solution, follow first order kinetic laws up to ca. $60 \%$ diperoxide conversion at temperature from $130.0^{\circ} \mathrm{C}$ to $166.0^{\circ} \mathrm{C}$ and an $1.00 \times 10^{-3} \mathrm{~mol} \cdot \mathrm{L}^{-1}$ initial concentration.

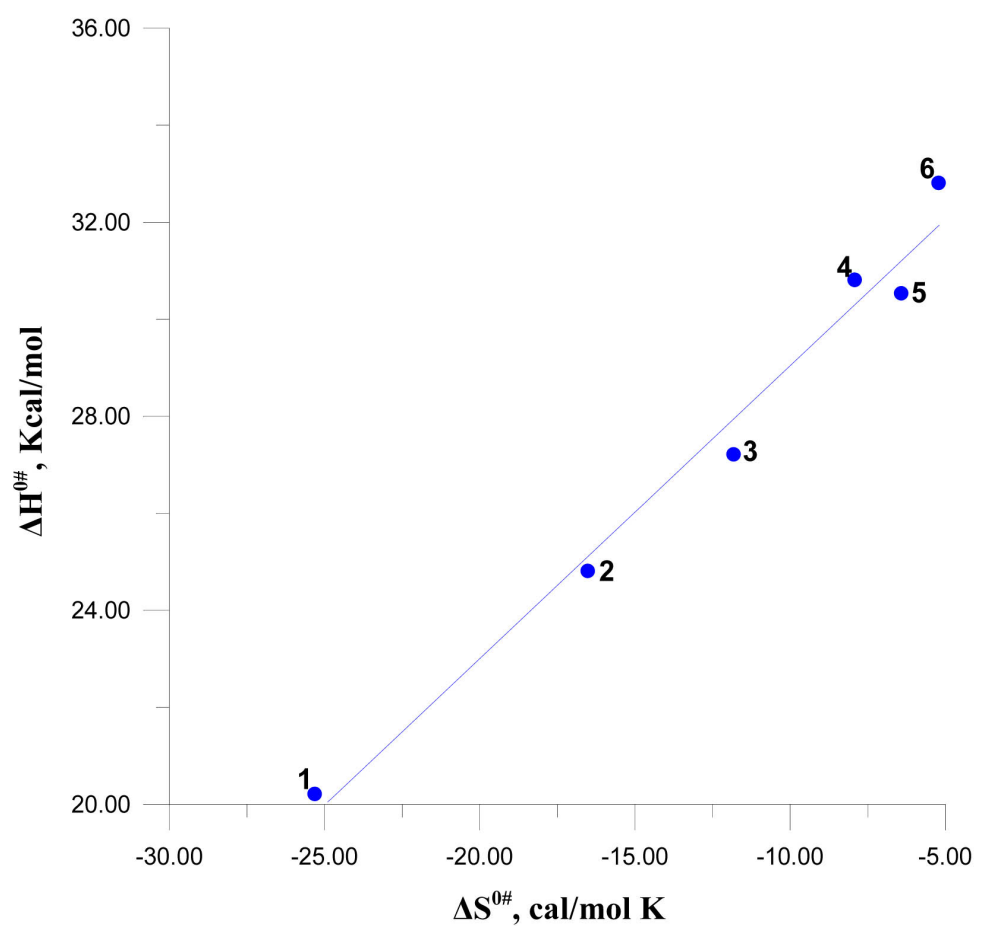

Figure 3. Representation of the "Isokinetic Ratio" according to the Leffler treatment for the unimolecular thermolysis of DFT in 1-Metilcellosolve; 2-Methanol; 3-Tetrahydrofuran; 4-Toluene; 5-Chlorobenzene; 6-Benzene. 
The reaction products and the activation parameter values contribute to postulate the mechanism for the thermolysis of DFT in chlorobenzene. The thermolysis follows the same mechanism of decomposition for other tetroxanes, which begins with the homolytic rupture of the peroxydic bond, $\mathrm{C}-\mathrm{C}$ leading to the formation of an intermediate biradical and then $\mathrm{C}-\mathrm{O}$ bond ruptures giving benzaldehyde and oxygen molecule as final products.

The concentration at which the thermolysis reaction of the DFT was studied was very low, whereby the effects of secondary decomposition reactions induced by free radicals originated in the reaction medium can be considered minimal or negligible.

In chlorobenzene, the thermolysis of the DFT follows the same reaction pathway as in other solvents studied.

\section{Conflicts of Interest}

The authors declare no conflicts of interest regarding the publication of this paper.

\section{References}

[1] Jorge, N.L. and Castro, E.A. (2009) Structure and Properties. Trends in Organic Chemistry, 13, 65-74.

[2] Smith, M.B. and March, J. (2007) March's Advances Organic Chemistry. 6th Edition, Wiley \& Sons, New Jersey.

[3] Acuña, P. and Morales, G. (2011) Síntesis de poliestireno de alto impacto (hips) a partir de diferentes iniciadores multifuncionales: efecto de la estructura y del contenido de oxígeno activo del iniciador. Rev. Iberoam. Polim., 12, 160-168.

[4] Dong, Y., McCulloug, K.J., Wittlin S., Chollet, J. and Vennerstrom J.L. (2010) The Structure and Antimalarial Activity of Dispiro-1,2,4,5-Tetraoxanes Derived from (+)-Dihydrocarvone. Bioorganic \& Medicinal Chemistry Letters, 20, 6359-6361. https://doi.org/10.1016/j.bmcl.2010.09.113

[5] Atheaya, H., Khan, S.I., Mamgaina, R. and Rawata, D.S. (2008) Synthesis, Thermal Stability, Antimalarial Activity of Symmetrically and Asymmetrically Substituted Tetraoxanes. Bioorganic \& Medicinal Chemistry Letters, 18, 1446-1452. https://doi.org/10.1016/j.bmcl.2007.12.069

[6] Creek, D.J., Ryan, E., Charman, W.N., Chiu, F.C., Prankerd, R.J., Vennerstrom, J.L. and Charman, S.A. (2009) Stability of Peroxide Antimalarials in the Presence of Human Hemoglobin. Antimicrobial Agents and Chemotherapy, 53, 3496-3500. https://doi.org/10.1128/AAC.00363-09

[7] Oxley, J.C., Smith, J.L. and Chen, H. (2002) Decomposition of a Multiperoxidic Compound: Triacetone Triperoxide (TATP). Propellants, Explosives, Pyrotechnics, 27, 209-216. https://doi.org/10.1002/1521-4087(200209)27:4<209::AID-PREP209>3.0.CO;2-J

[8] Leiva, L.C.A., Jorge, N.L., Romero, J.M., Cafferata, L.F.R., Gómez Vara, M.E. and Castro, E.A. (2008) Decomposition of the Acetone Cyclic Diperoxide in Octanol Solution. Journal of the Argentine Chemical Society, 96, 110-122.

[9] Profeta, M.I., Romero, J.M., Leiva, L.C.A., Jorge, N.L., Gómez Vara, M.E. and Castro, E.A. (2011) Solvent Effect of Oxygen in the Thermolisys Decomposition of the 
Acetone Diperoxide. International Journal of Chemoinformatics and Chemical Engineering, 1, 96-102. https://doi.org/10.4018/ijcce.2011010107

[10] Jorge, N.L., Romero, J.M., Grand, A. and Hernández-Laguna, A. (2012) Gas Phase Thermolysis Reaction of Formaldehyde Diperoxide. Kinetic Study and Theoretical Mechanisms. Chemical Physics, 39, 37-45.

https://doi.org/10.1016/j.chemphys.2011.11.019

[11] Jorge, N.L., Hernandez-Laguna, A. and Castro, E.A. (2013) Some Recent Developments on the Synthesis, Chemical Reactivity, and Theoretical Studies of Tetroxanes. International Journal of Chemoinformatics and Chemical Engineering, 3, 48-73. https://doi.org/10.4018/ijcce.2013010105

[12] Reguera, M.B., Frette, S.G., Romero, J.M., Jorge, N.L. and Castro, E.A. (2012) Synthesis and Thermical Decomposition Reaction of 3,6-Dibutanoic-1,2,4,5-Tetroxane in Solution. Bentham Science, 4, 1-4.

[13] Pila, A.N., Profeta, M.I., Romero, J.M., Jorge, N.L. and Castro, E.A. (2012) Kinetics and Mechanism of the Thermal Decomposition Reaction of 3,6-Diphenyl-1,2,3,5Tetroxane in Solution. International Journal of Chemical Modeling, 4, 405-411.

[14] Bordón, A.G., Profeta, M.I., Romero, J.M. and Jorge, N.L. (2015) Thermal Decomposition of Benzaldehyde Diperoxide in Isopropyl Alcohol, Effect of Solvent Polarity. Asian Journal of Science and Technology, 6, 1928-1932.

[15] Jorge, N.L., Gómez Vara, M.E., Castro, E.A., Autino, J.C. and Cafferata, L.F.R. (1999) Experimental and Theoretical Study of trans-3,6-diphenyl 1,2,4,5-Tetroxane Molecule. Journal of Molecular Structure: THEOCHEM, 459, 29-35. https://doi.org/10.1016/S0166-1280(98)00254-1

[16] Huyberechts, S., Halleux, A. and Kruys, P. (1955) Une application de Calcule. Statistique a le Cinétique Chimique. Bulletin des Sociétés Chimiques Belges, 64, $203-$ 209. https://doi.org/10.1002/bscb.19550640502

[17] Exner, O. (1972) Statistic of the Enthalpy-Entropy Relationship. I. The Special Case. Collection of Czechoslovak Chemical Communications, 27, 1425-1444. https://doi.org/10.1135/cccc19721425

[18] Leffler, J.E. (1955) The Enthalpy-Entropy Relationship and Its Implications for Organic Chemistry. The Journal of Organic Chemistry, 20, 1202-1231. https://doi.org/10.1021/jo01126a009 